\title{
Cleavage at the 586 Amino Acid Caspase-6 Site in Mutant huntingtin Influences Caspase-6 Activation In Vivo
}

\author{
Rona K. Graham, ${ }^{1}$ Yu Deng, ${ }^{1}$ Jeffery Carroll, ${ }^{1}$ Kuljeet Vaid, ${ }^{1}$ Catherine Cowan, ${ }^{2}$ Mahmoud A. Pouladi, ${ }^{1}$ \\ Martina Metzler, ${ }^{1}$ Nagat Bissada, ${ }^{1}$ Lili Wang, ${ }^{1}$ Richard L. M. Faull, ${ }^{3}$ Michelle Gray, ${ }^{4}$ X. William Yang, ${ }^{4}$ \\ Lynn A. Raymond, ${ }^{2}$ and Michael R. Hayden ${ }^{1}$ \\ ${ }^{1}$ Centre for Molecular Medicine and Therapeutics, Child and Family Research Institute, Departments of ${ }^{1}$ Medical Genetics and ${ }^{2}$ Psychiatry, Brain Research \\ Centre, University of British Columbia, Vancouver, British Columbia, Canada V5Z 4H4, ${ }^{3}$ Department of Anatomy with Radiology, University of Auckland, \\ Auckland 1142, New Zealand, and ${ }^{4}$ Center for Neurobehavioral Genetics, Semel Institute for Neuroscience and Human Behavior, Department of Psychiatry \\ and Biobehavioral Sciences, Brain Research Institute, David Geffen School of Medicine, University of California, Los Angeles, Los Angeles, California, \\ 90095-1761
}

Caspase cleavage of huntingtin (htt) and nuclear htt accumulation represent early neuropathological changes in brains of patients with Huntington's disease (HD). However, the relationship between caspase cleavage of htt and caspase activation patterns in the pathogenesis of HD remains poorly understood. The lack of a phenotype in YAC mice expressing caspase-6-resistant (C6R) mutant htt (mhtt) highlights proteolysis of htt at the 586 aa caspase- 6 (casp6) site as a key mechanism in the pathology of HD. The goal of this study was to investigate how proteolysis of htt at residue 586 plays a role in the pathogenesis of $\mathrm{HD}$ and determine whether inhibiting casp6 cleavage of mhtt alters cell-death pathways in vivo. Here we demonstrate that activation of casp6, and not caspase-3, is observed before onset of motor abnormalities in human and murine HD brain. Active casp6 levels correlate directly with CAG size and inversely with age of onset. In contrast, in vivo expression of C6R mhtt attenuates caspase activation. Increased casp6 activity and apoptotic cell death is evident in primary striatal neurons expressing caspase-cleavable, but not C6R, mhtt after NMDA application. Pretreatment with a casp6 inhibitor rescues the apoptotic cell death observed in this paradigm. These data demonstrate that activation of casp6 is an early marker of disease in HD. Furthermore, these data provide a clear link between excitotoxic pathways and proteolysis and suggest that C6R mhtt protects against neurodegeneration by influencing the activation of neuronal cell-death and excitotoxic pathways operative in HD.

\section{Introduction}

Huntington's disease (HD) is characterized by progressive cognitive decline and selective neuronal loss first evident in the striatum (Vonsattel et al., 1985). Early neuropathological changes include the appearance of N-terminal nuclear htt fragments, increases in the excitotoxic markers quinolinate and 3-hydroxykynurenine, and increased levels of glutamate (Taylor-Robinson et al., 1996; Wellington et al., 2002; Guidetti et al., 2004).

Proteolytic cleavage of mutant huntingtin (mhtt) appears to be a critical event in the pathogenesis of HD. Expression of mhtt fragments are toxic (Mangiarini et al., 1996; Hackam et al., 1998; Ratovitski et al., 2007), and accumulation of N-terminal trun-

\footnotetext{
Received April 22, 2010; revised Aug. 5, 2010; accepted Aug. 14, 2010.

This work was supported by the Cure Huntington Disease Initiative (TREAT-HD), Huntington's Disease Society of America Grant 20R69538, Canadian Institute of Health Research Grant CGD-85375, Michael Smith Foundation for Health Research Grant RKG 00495(06-1)BM, Health Research Council of New Zealand Grant 08/051, and Neurological Foundation of New Zealand Grant 0910-PG. X.W.Y is supported by National Institute of Neurological Disorders and Stroke/National Institutes of Health Grant R01 NS049501 and a research contract from Hereditary Disease Foundation. M.R.H. is a Killam University Professor and holds a Canada Research Chair in Human Genetics. We thank members of our laboratory, in particular Simon Warby, Zoe Murphy, Mark Wang, Lily Y. J. Zhang, and Esther G. X. Yu, for their support. Additional human tissue samples were kindly provided by Jean-Paul Vonsattel at the New York Brain Bank. We thank Andréa C. LeBlanc for the gift of the casp6-cleaved tau antibody.

Correspondence should be addressed to Michael R. Hayden, Centre for Molecular Medicine and Therapeutics, University of British Columbia, 980 West 28th Avenue, Vancouver, BC, Canada V5Z4H4. E-mail: mrh@cmmt.ubc.ca. DOI:10.1523/JNEUROSCI.2071-10.2010

Copyright $\odot 2010$ the authors $\quad 0270-6474 / 10 / 3015019-11 \$ 15.00 / 0$
}

cated products of htt are observed early in HD brain (Kim et al., 2001; Wellington et al., 2002). Increasing evidence supports the importance of the specific protein context of mhtt fragments in initiating toxic signaling pathways specific to HD (Yu et al., 2003; Slow et al., 2005; Graham et al., 2006a).

htt is proteolytically cleaved by caspases (Wellington et al., 2000; Kim et al., 2001), releasing an N-terminal fragment containing the glutamine tract. Eliminating cleavage at the 586 aa caspase-6 (casp6) site of mhtt (C6R mhtt) is sufficient to preserve striatal volume and behavioral disturbances in a YAC model of HD (Graham et al., 2006a; Pouladi et al., 2009). Furthermore, C6R mice are resistant to NMDA receptor (NMDAR)-mediated excitotoxicity (Graham et al., 2006a; Milnerwood et al., 2010). The lack of an HD phenotype in the C6R mice demonstrates that cleavage at the casp6 site plays a key role in the development of $\mathrm{HD}$ and implicates casp6 as a critical target in HD.

Apoptosis is a genetically programmed form of cell death that uses caspases. Casp6 was originally identified as an executioner caspase because of its role in cytoskeletal alterations and cleavage of nuclear lamins. However, casp6 has since been shown to also function as an initiator caspase through its ability to cleave and activate casp2 and casp3 (Xanthoudakis et al., 1999; Allsopp et al., 2000; Henshall et al., 2002), and active casp6 is present in preclinical Alzheimer's disease (AD) brains that do not have cellular apoptotic morphology (Albrecht et al., 2007). 
Proteolytic cleavage of specific substrates has also been demonstrated to be an important cellular event in the pathogenesis of AD (Gervais et al., 1999; Guo et al., 2004) and spinocerebellar ataxia (Garden et al., 2002). Interestingly, in a mouse model of $\mathrm{AD}$, mutation of the casp6 cleavage site at Asp664 in the amyloid $\beta$ precursor protein (APP) suppressed synapse loss, dentate gyral atrophy, and memory loss (Galvan et al., 2006, 2008; Saganich et al., 2006; Zhang et al., 2010).

Accumulation of nuclear htt fragments is delayed in the C6R mice (Graham et al., 2006a), suggesting that inhibiting casp6 cleavage of mhtt alters proteolytic pathways active in the early stages of HD. In striatal neurons exposed to staurosporine, activation of casp6 is observed and active casp6 translocates to the nucleus and colocalizes with the 586 aa htt fragments, suggesting that nuclear localization is important for the neurotoxicity of this fragment (Warby et al., 2008).

We have previously determined in vitro that casp6 cleaves htt at the IVLD 586 a site (Wellington et al., 2000; Graham et al., 2006a). casp6 interacts with htt and dominant-negative inhibition of casp 6 activity in primary striatal neurons protects neurons from degeneration (Hermel et al., 2004). If casp6 is an essential rate-limiting step in the pathogenesis of $\mathrm{HD}$, it may be expected that casp6 activation occurs early in the disease process. We therefore set out to determine the natural history of casp 6 activation patterns in human and murine HD brain. Furthermore, based on previous findings, we aimed to explore the underlying mechanism of the neuroprotection observed in the C6R mice.

\section{Materials and Methods}

Protein analysis and Western blotting. Human brain tissue was obtained from the Canadian Brain Tissue Bank, New York Brain Bank, and Neurological Foundation of the New Zealand Human Brain Bank. Ethical approval was obtained from the University of British Columbia review committee (CW06-0171/H06-70410). Human or murine tissue protein lysates and Western blots were prepared as described previously (Slow et al., 2003). Membranes were probed with $\alpha$ casp6 (catalog \#0703; MBL International) or $\alpha$ casp3 (catalog \#557035; BD Pharmigen). Densitometric values from scanned Western blots were obtained using Quantity One software (Bio-Rad).

CAG size. DNA was extracted from leukocytes and CAG repeat assessed as described previously (Andrew et al., 1994).

HD transgenic mice. YAC128 and C6R (lines C6R7 and C6R13) mice were identified as described (Slow et al., 2003; Graham et al., 2006), and tissues were harvested according to University of British Columbia Animal Protocol A07-0106. BACHD mice are as described previously (Gray et al., 2008).

Immunohistochemistry. Mouse brains were fixed, sectioned, and immunoassayed as described previously (Slow et al., 2003; Graham et al., 2006a,b) with casp6 (catalog \#9761; Cell Signaling Technology), casp3 (catalog \#9661; Cell Signaling Technology), or casp6-cleaved tau (Guo et al., 2004). No staining was observed in a negative control without primary antibody. Photographs were taken on a light microscope (Carl Zeiss).

Fluorogenic caspase activity assay. The protein concentration of tissue lysates (prepared as described above) was measured using the Bradford assay. The lysate was incubated with the reaction mix (as per the instructions of the manufacturer) containing the fluorogenic casp6 substrate Ac-VEID-AFC (acetyl-Val-Glu-Ile-Asp-7-amino-4-methylcoumarin) (BIOMOL Research Laboratories) at $50 \mu \mathrm{m}$ in $100 \mu \mathrm{l}$ of reaction volume at $37^{\circ} \mathrm{C}$ for $1 \mathrm{~h}$. The fluorescent units were read at $405 \mathrm{~nm}$ excitation and $535 \mathrm{~nm}$ emission. The micromolar AFC was calculated against the AFC standard curve and normalized to protein concentration. The relative casp6 activity is expressed as micromolar AFC per milligram of protein. casp3 activity was assayed as above with Ac-DEVD-AFC (acetyl-Asp-Glu-Val-Asp-7-amino-4-methylcoumarin) (BIOMOL Research Laboratories) as substrate.
NMDAR-mediated excitotoxicity. Cultures were maintained in vitro for 9-10 d, after which they were exposed to balanced salt solution (BSS) or $500 \mu \mathrm{M}$ NMDA (Sigma) in BSS for $10 \mathrm{~min}$ in a procedure described previously (Zeron et al., 2002; Graham et al., 2006a,b). Cells were fixed 4 or $6 \mathrm{~h}$ after NMDA with $4 \%$ paraformaldehyde (PFA) in PBS. Cells were permeabilized in $0.5 \%$ Triton X-100/1\% PFA in PBS and then blocked in $3 \%$ NGS in PBS and incubated in active-casp6 antibody (catalog \#9761; Cell Signaling Technology) at 1:500 in 2\% NGS in PBS. Secondary antirabbit Alexa Fluor-584 (Invitrogen) was used at 1:800 in 2\% NGS in PBS. Neurons were counterstained with $10 \mu \mathrm{M}$ Hoechst and then mounted with Fluormount (Southern Biotechnology). In each experiment, a negative control without primary antibody was included. To assess percentage of medium spiny neurons (MSNs) positive for active casp6, the experimenter was blinded to conditions and took six pairs of photographs per coverslip using a $63 \times$ objective (Carl Zeiss axiophot microscope). The intensities of light captured for individual MSNs were then measured using Northern Eclipse software, and all MSNs with intensities of more than 2 SDs greater than the mean intensity of negative control MSNs were considered to be immunopositive. For casp6 mRNA analysis, total RNA was extracted from BSS- or NMDA-treated MSNs (3.5 h after treatment) with RNeasy Micro kit (Qiagen). First-strand cDNA was prepared using SuperScript III First-Strand Synthesis System (Invitrogen). $1 / 100$ of the first-strand cDNA was used as template in real-time PCR reaction in a final volume of $10 \mu \mathrm{l}$. The sequences of the casp6 primers were 5'TGGCTCCTGGTACATTCAGGAT 3 ' and 5' TCCGTGAACTCCAGGGAACT 3 , and the $\beta$-actin primers were $5^{\prime}$ ACGGCCAGGTCATCACTATTG $3^{\prime}$ and $5^{\prime}$ CAAGAAGGAAGGCTGGAAAAGA $3^{\prime}$. $\Delta \Delta$ Ct comparative assay was performed using the ABI 7500 Fast RealTime PCR System and Power SYBR Green PCR Master Mix (Applied Biosystems). All samples were run in triplicate and done for three separate cultures. Primary data analysis was performed using system software from Applied Biosystems. Relative quantification was used to analyze the results. casp6 activity assays were performed on BSS- or NMDA-treated MSN lysate $3.5 \mathrm{~h}$ after treatment as described above. For assessment of apoptotic cell death, cultures were prepared and exposed to BSS, $500 \mu \mathrm{M}$ NMDA (Sigma), $500 \mu \mathrm{M}$ NMDA plus casp6 inhibitor z-VEID-fmk (benzyloxycarbonyl-Val-Glu-Ile-Asp-fluoromethylketone) (catalog \#218757; Calbiochem), or $500 \mu \mathrm{M}$ NMDA plus casp3 inhibitor z-DEVDfmk (benzyloxycarbonyl-Asp-Glu-Val-fluoromethyl ketone) (catalog \#264155; Calbiochem) for $10 \mathrm{~min}$. Neurons with the caspase inhibitor were pretreated for $1 \mathrm{~h}$ with either $5 \mu \mathrm{M}$ z-VEID-fmk or z-DEVD-fmk before NMDA application. Twenty-four hours after NMDA, cultures were fixed and assessed for apoptotic cell death as described previously (Graham et al., 2006a,b).

Statistical analysis. Statistical analysis was done using Student's $t$ test, one-way ANOVA (in cases of significant effect of genotype, post hoc comparisons between genotypes were performed using Turkey's or linear trend post hoc test). $p$ values, SEM, means, and SDs were calculated using Prism version 4.0 (GraphPad Software). Linear regression analysis for $r^{2}$ and $p$ values was calculated by Pearson's correlation coefficient. Differences between means were considered statistically significant if $p<0.05$.

\section{Results}

Activation of caspase- 6 is an early feature in patients with HD To investigate whether apoptotic pathways in human HD brain correlate with the findings in the YAC128 model of HD, we first determined whether normal aging alone influences activation of casp6. In tissues from individuals younger than 50 years of age, the inactive $\mathrm{p} 34$ proform of casp6 is detected in the striatum and frontal cortex of human control tissue (Fig. 1A,B). However, starting in the fifth decade and thereafter, a decrease in the proform of casp6 is observed with a concomitant increase in the active p20 fragment of casp6 (Fig. $1 A, B$ ). In general, increases in caspase activation and activity are associated with a decrease in the proform and an increase in the activated form of the specific caspase (Zhang et al., 2003). Comparison of relative active casp6 striatal expression levels in binned age samples reveals a signifi- 

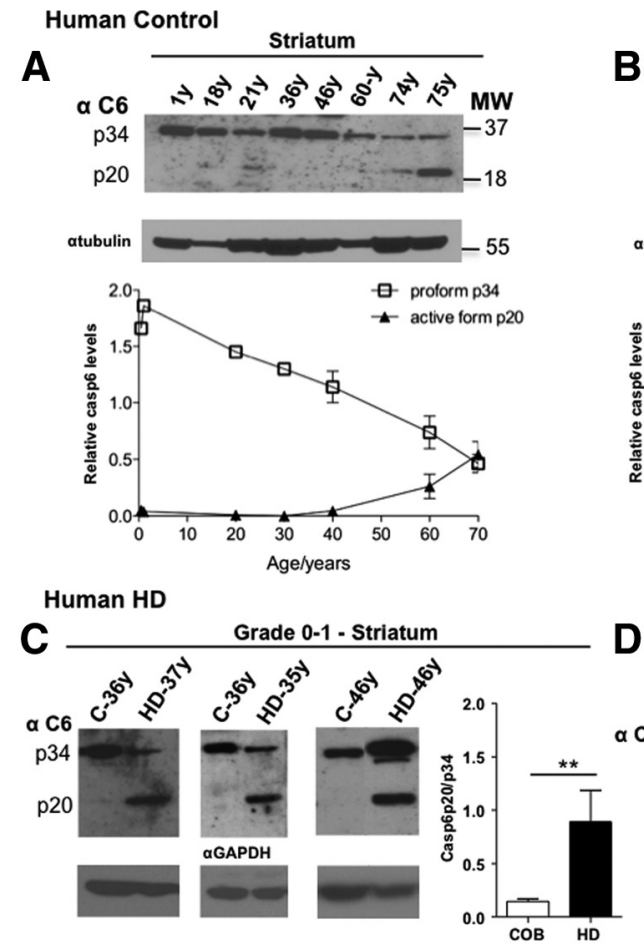

D
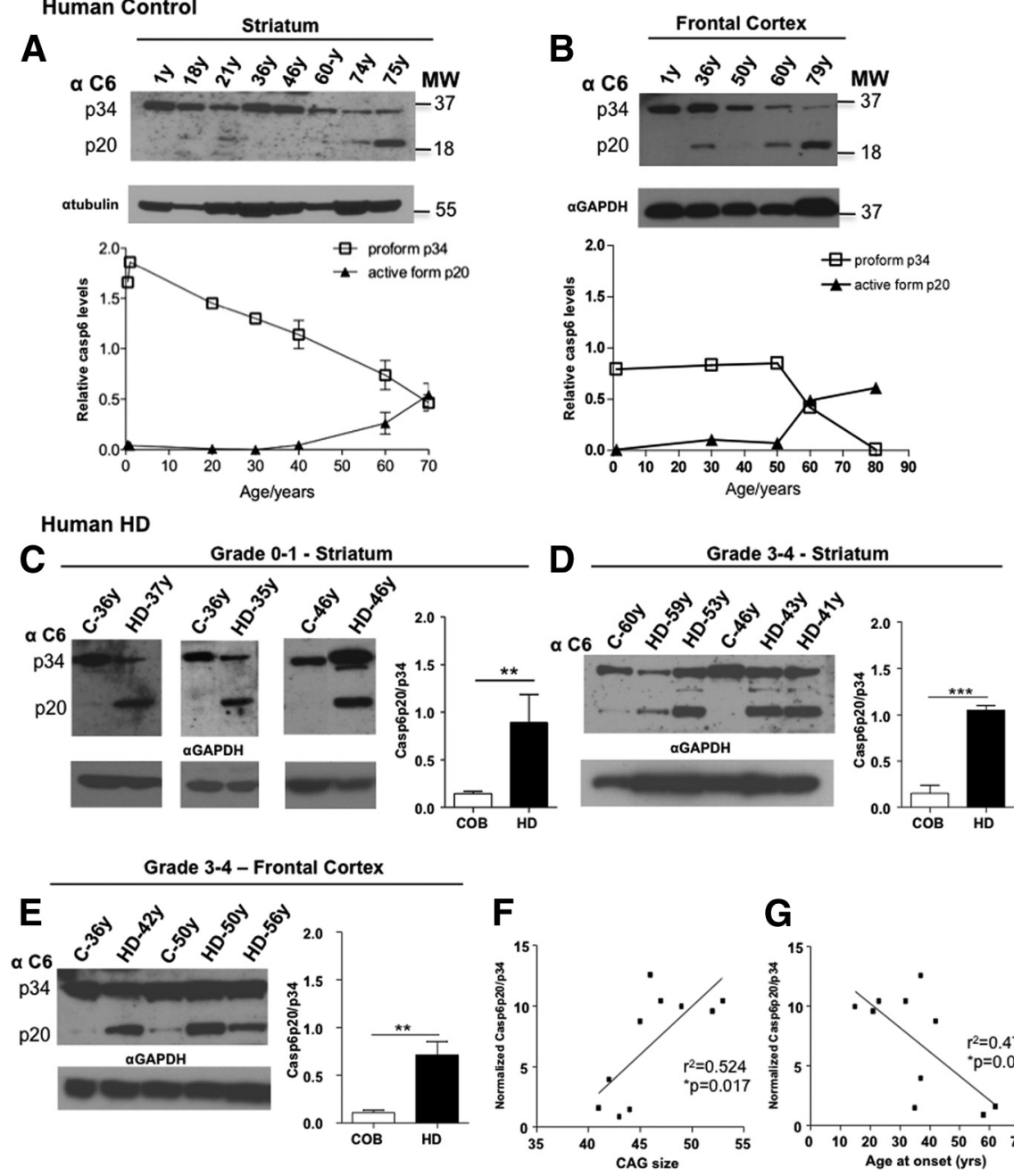

Figure 1. Activation of caspase- 6 is an early event in human HD striatum and correlates with CAG size. $A, B$, After the fifth decade, a decrease in the proform of casp6 is observed in the striatum and frontal cortex of human control tissue with a concomitant increase in the active p20 fragment of casp6. $\boldsymbol{C}$, Increased levels of the active p20 form of casp6 are observed in early-grade human HD striatum compared with control brain $(p<0.01)$. D, E, Grade 3-4 human HD striatum and frontal cortex similarly demonstrate increased active $\mathrm{p} 20$ casp6 compared with control tissue ( $p<0.001$ and $p<0.01$, respectively). Glyceraldehyde3-phosphate dehydrogenase (GAPDH) demonstrates loading for all tissues. Representative immunoblots are shown for casp6. $\boldsymbol{F}, A$ positive correlation is observed between striatal expression of normalized active casp6 levels and CAG size $\left(F_{(1,8)}=8.9, r^{2}=\right.$ $0.524, p=0.017)$. $\mathbf{G}$, Comparison of age of onset and normalized levels of active casp6 reveals an inverse correlation between these two variables $\left(F_{(1,8)}=7.1, r^{2}=0.471, p=0.02\right)$. Levels of casp6 have been corrected for equal loading with tubulin or GAPDH. Mean measurements and densitometric ratios of casp6p20/p34 and relative casp6 levels are \pm SD. ${ }^{* *} p<0.01$; ${ }^{* * *} p<$ 0.001. MW, Molecular weight; $\mathrm{COB}$, Control.

cant difference in active casp6 expression levels with age (ANOVA, $p=0.0061$, post hoc; $0-20$ vs $60-80$ years, $p<0.05$; $20-40$ vs $60-80$ years, $p<0.05$ ). None of the older individuals from whom control tissue was obtained died of a neurodegenerative disease nor were there any other factors that could account for the active casp6 observed with advanced age in control tissues. Demographics on the human control tissues is included in supplemental Table 1 (available at www.jneurosci.org as supplemental material).

We next investigated expression levels of casp6 in human HD grade $0-1$ and control striatum by Western blot. In age-matched human brain tissue, increased levels of the active p20 form of casp6 are observed in early-grade HD striatum compared with control brain (Fig. 1C) $(p<0.01, n=3)$, demonstrating that casp6 is processed and activated early in the pathogenesis of HD. These patients were aged 35-46 years. Importantly, we observe

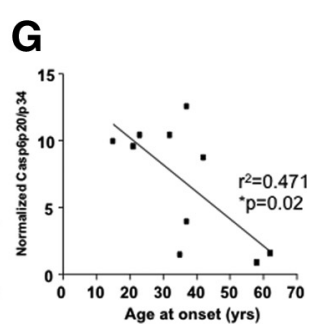

active casp6 in brain tissue from a presymptomatic individual $\sim 15$ years before predicted onset [ $>90 \%$ conditional probability to have onset within 15 years (Langbehn et al., 2004), age at death of 37 years, $45 \mathrm{CAG}$ repeat, grade 0 ]. Of note, a review of transcriptional profiling studies performed on control and HD human brain tissue reveal that casp6 mRNA is increased in early-grade $(0-2)$ human HD caudate and motor cortex compared with control tissue (Hodges et al., 2006).

Analysis of grade 3-4 human HD striatum and frontal cortex similarly demonstrates increased active p 20 casp6 in brains of HD patients compared with control tissue (age-matched, $p<0.001, n=5 ; p<$ $0.01, n=6$, respectively), as observed previously (Hermel et al., 2004), implying that cleavage and activation of casp6 is also evident in end-stage $\mathrm{HD}$ (Fig. $1 D, E$ ). In this particular sense, this implies accelerated aging in the brains of human HD individuals.

If caspase activation is key to the pathogenesis of HD and the severity of illness, one would predict that CAG size might modulate this effect. To examine the influence of CAG size on casp6 activation in human HD brain, we plotted CAG size against normalized levels of active casp6 in the respective grade 3-4 HD brain sample. A positive correlation is observed between striatal levels of active casp6 and CAG size (Fig. $1 F)\left(F_{(1,8)}=8.9\right.$, $r^{2}=0.524, p=0.017$, age at death of 41-75 years, $n=10$ ). Furthermore, comparison of age of onset and normalized levels of active casp6 reveals an inverse correlation between these two variables (Fig. $1 G)\left(F_{(1,8)}=7.1, r^{2}=0.471, p=\right.$ $0.02, n=10)$. However, although there is a linear correlation between CAG size and expression levels of active casp6 in the striatum, there is no correlation with active casp6 and duration of disease $\left(r^{2}=\right.$ $0.1948, p=0.202$ ).

Active p20 casp6 levels also correlate with CAG size in human frontal cortex brain tissue $\left(F_{(1,8)}=6.2, r^{2}=0.470, p=0.04\right.$, CAG range of $42-53$, age at death of $41-75$ years, $n=10$ ) and there is a trend toward an inverse correlation with age of onset $\left(F_{(1,8)}=3.4\right.$, $\left.r^{2}=0.302, p=0.10, n=10\right)$. This correlation with CAG size points to a fundamental mechanism contributing to how longer polyglutamine stretches are associated with a more severe disease phenotype. If casp6 activation were important in the pathogenesis of $\mathrm{HD}$, one might expect predominant casp6 activation in those regions of the brain in which selective neuronal loss is most evident, and these data suggest that this activation is influenced by CAG size.

To investigate the relationship of casp6 to the pathogenesis of HD in more detail, we assessed casp6 in the YAC128 model in which we are not limited by the availability of presymptomatic tissue. 
Caspase- 6 activation pathways are observed early and selectively in the YAC128 mouse model of HD

Coronal sections of wild-type (WT), YAC128 (HD53), and C6R mice were stained with an antibody specific for the active form of casp6 at 3, 9, 12, and 18 months of age $(n=3)$. In WT murine brain, active casp6 is detected predominantly in medium-sized striatal neurons starting at 9 months with an increase at 18 months of age (Fig. $2 A a-A d$ ), similar to the age-related effect observed in the human control tissue. In contrast, active casp6 is detected in medium-sized striatal neurons of YAC128 mice by 3 months with levels increasing with age (Fig. $2 \mathrm{Ae}-$ $A h)$, suggesting that at least one component of accelerated aging is occurring in the YAC128 mice similar to that observed in human HD brain.

Increases in casp6 activation in YAC128 striatum versus WT at 3 months is further confirmed in vivo by measurement of casp6 activity in protein lysates using the fluorogenic substrate VEID-AFC (Fig. $2 B$ ) ( $t$ test, $p=0.006, n=8)$. Increased casp6 activity in YAC128 striatum compared with WT is also observed at 12 and 18 months of age (Fig. $2 C, D)(t$ test, WT vs YAC128: 12 months, $p=0.0004, n=15 ; 18$ months, $p=0.006$, $n=9$ ).

In the striatum of two lines of mice expressing C6R mhtt (C6R7 and C6R13), low levels of activated casp6 are observed at 3 months with no change as the animals age (Fig. $2 A i-A p$ ). Measurement of casp6 activity in C6R striatum reveals decreased casp6 activity in C6R striatum compared with YAC128 (Fig. 2B: 3 months, ANOVA, $p=0.004$; WT vs YAC128, $p<$ 0.05; C6R vs YAC128, $p<0.01, n=8$; Fig. $2 C$ : 12 months, ANOVA, $p<0.003$; WT vs YAC128, $p<0.01$; C6R vs YAC128, $p<$ $0.05, n=15$; Fig. $2 D: 18$ months, ANOVA, $p=0.018$; WT vs YAC128, $p<$ 0.05 ; WT vs C6R, $p>0.05, n=9)$.

To determine whether the active casp6 detected by immunostaining and the increases observed in casp6 activity in the YAC truly represents active casp6 in vivo, we assessed coronal sections from WT, YAC128, and C6R mice $(n=3,18 \mathrm{~m})$ using the neo-epitope antibody to casp6cleaved tau, which specifically recognizes tau cleaved at the VSGD 314 aa casp6 site (Guo et al., 2004). This antibody strongly immunostained medium-sized striatal neurons in YAC128 striata and to a lesser extent in WT and C6R striatum, correlating with the active casp6 immunostaining observed (Fig. 2E).

At 3 months of age, active casp6 is not observed in WT or YAC128 cortex using immunohistochemistry, and there is no differ-

E $100 \times$. Scale bar, $10 \mu \mathrm{m}$.
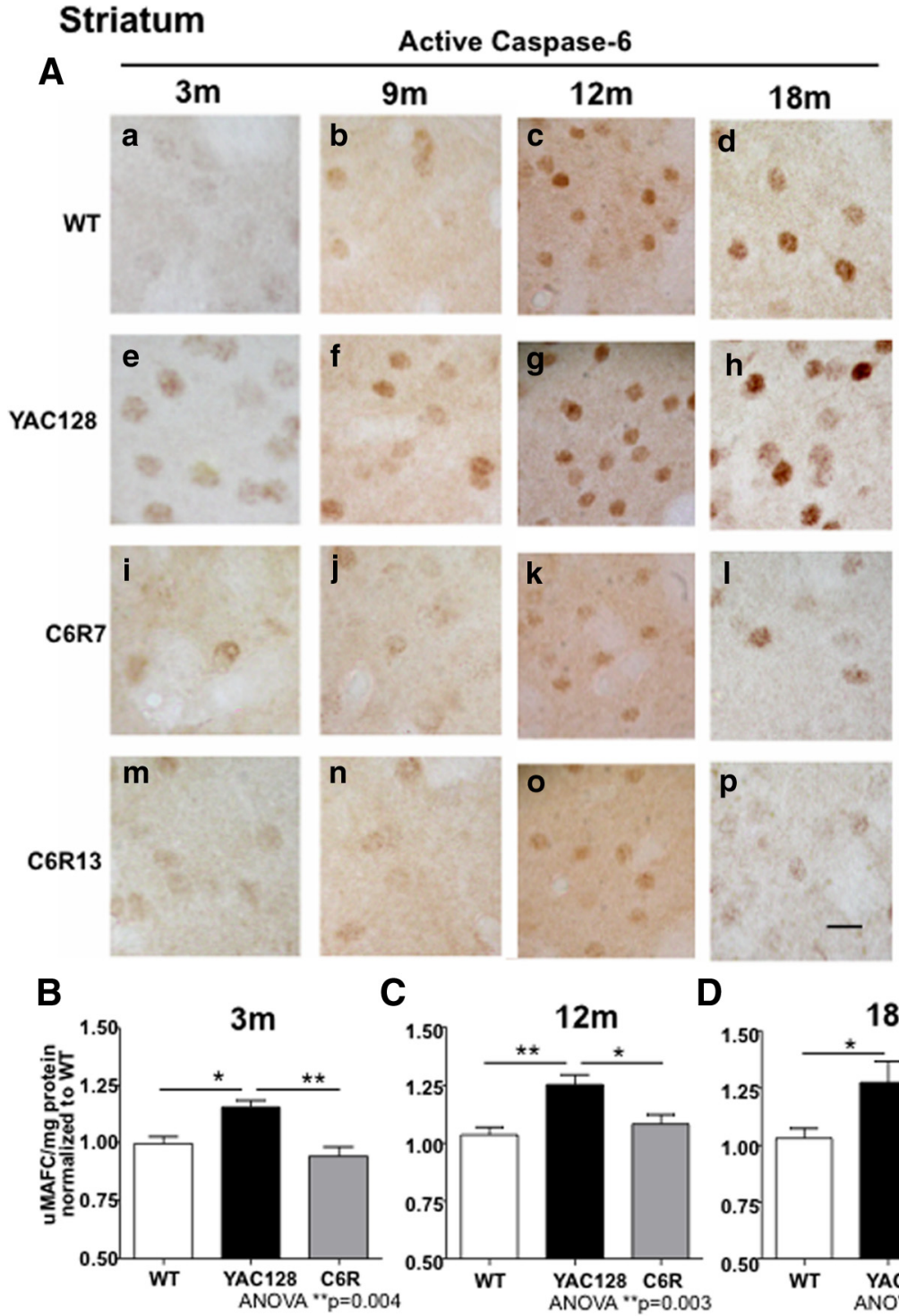

C
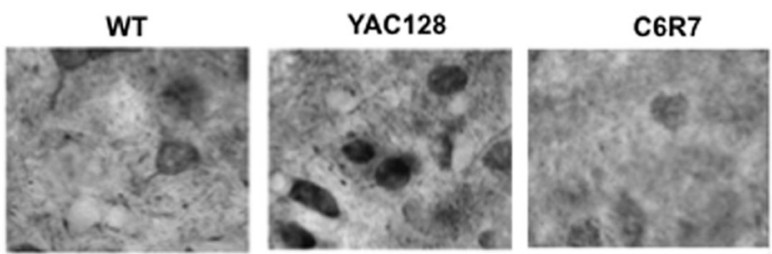

aCaspase- 6 cleaved tau
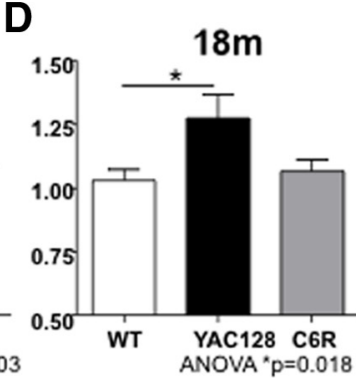

Figure 2. Accelerated activation of caspase-6 is observed in the striatum of YAC128 mice compared with wild-type and C6R mice. $\boldsymbol{A}$, In WT murine brain, active casp6 is detected predominantly in medium-sized striatal neurons starting at 9 months $(\boldsymbol{a}-\boldsymbol{d})$. Active casp 6 is detected in medium-sized striatal neurons of YAC128 mice by 3 months ( $\boldsymbol{e}-\boldsymbol{h})$. In the striatum of two lines of mice expressing (6R mhtt (C6R7 and C6R13), low levels of activated casp6 are observed at 3 months with no change as the animals age $(\boldsymbol{i}-\boldsymbol{p})$. $\boldsymbol{B}-\boldsymbol{D}$, Increased casp6 activity is observed in YAC128 striatum compared with WT and C6R striatum at 3 months (B) (ANOVA, $p=0.004$; WT vs YAC128, $p<0.05$; (6R vs YAC128, $p<0.01$ ), 12 months (C) (ANOVA, $p=0.003$; WT vs YAC128, $p<0.01$; (6R vs YAC128, $p<0.05$ ), and 18 months (D) (ANOVA, $p=0.018$; WT vs YAC128, $p<0.05$; WT vs $(6 R, p>0.05$ ) of age. $\boldsymbol{E}$, The neo-epitope antibody to casp6-cleaved tau strongly immunostains medium-sized striatal neurons in YAC128 striata and to a lesser extent in WT and (6R striatum (18 months). casp6 activity measurements are \pm SEM. ${ }^{*} p<0.05$; ${ }^{* *} p<0.01$. Magnification,

ence in baseline casp6 activity in protein lysates of WT and YAC128 cortex. In murine WT cortex, expression of active casp6 is observed predominantly in layers $2-5$ of the cortex commencing at 12 months of age with a moderate increase observed at 18 months (Fig. 3Aa$A f)$. In contrast, at 9 months of age, YAC128 cortex demonstrates 


\section{Cortex}

A
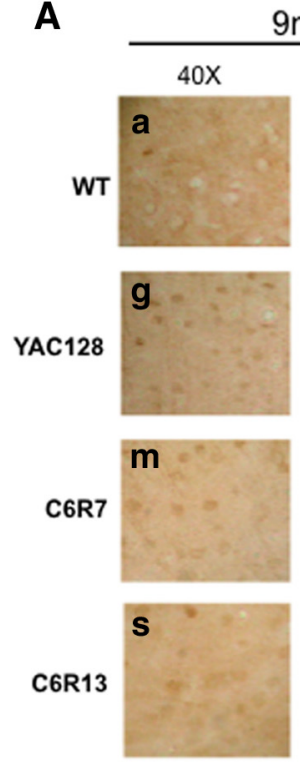

$9 m$
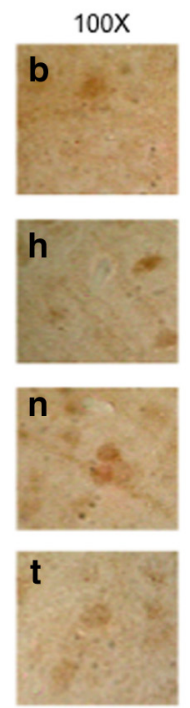

Active Caspase- 6 $12 \mathrm{~m}$
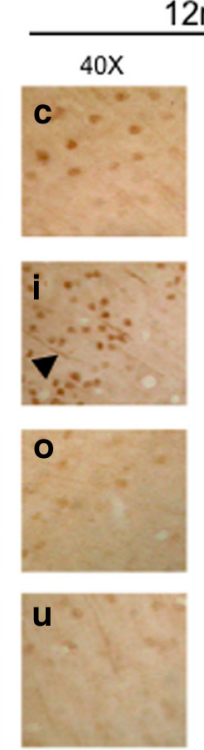
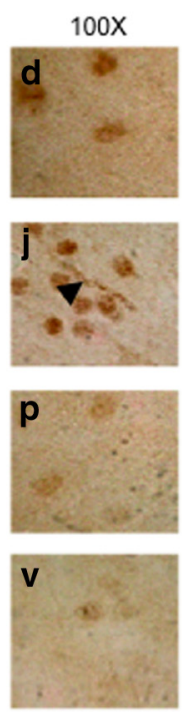
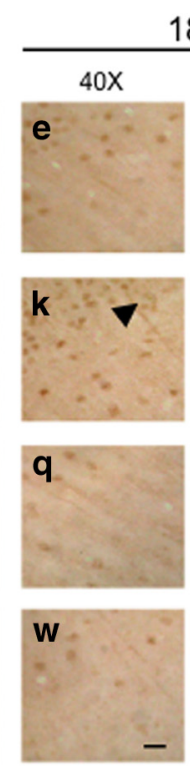

$18 \mathrm{~m}$
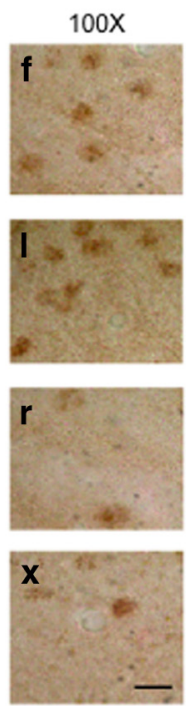

B

Caspase-6 activity
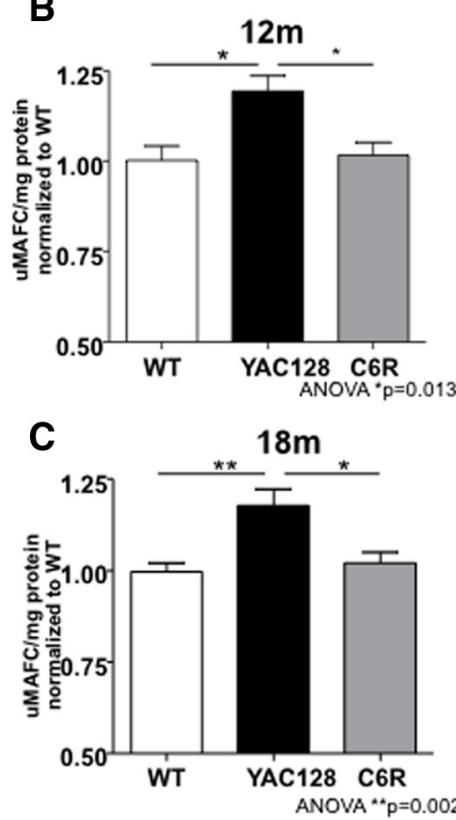

Figure 3. Caspase-6 activation is observed in YAC128 cortex subsequent to striatal activation. $\boldsymbol{A}$, In murine WT cortex, expression of active casp6 is observed predominantly in layers $2-5$ of the cortex commencing at 12 months of age $(\boldsymbol{a}-\boldsymbol{f})$. In contrast, at 9 months of age, YAC128 cortex demonstrates some immunopositive active casp6 stained neurons, and this increases with age $(\boldsymbol{g}-\boldsymbol{I})$. In mice expressing (6R mhtt (lines C6R7 and (6R13), a low level of immunopositive active casp6-stained neurons are observed at 12 and 18 months of age ( $\boldsymbol{m}-\boldsymbol{x}$ ). $\boldsymbol{B}, \boldsymbol{C}, A$ significant increase in casp6 activity is observed in YAC128 cortex compared with WT and C6R at 12 months (B) (ANOVA, $p=0.013$; WT vs YAC128, $p<0.05 ;(6 R$ vsYAC128, $p<0.05)$ and 18 months (C) (ANOVA, $p=0.002$; WT vs YAC128, $p<0.01$; (6R vsYAC128, $p<0.05)$ of age. Arrow points to active casp6 immunostaining on neurites. Casp6 activity measurements are \pm SEM. ${ }^{*} p<0.05 ;{ }^{* *} p<0.01$. Magnification, $40 \times$ and $100 \times$. Scale bars, $10 \mu \mathrm{m}$.

some immunopositive active casp6-stained neurons, and this increases with age (Fig. $3 A g-A l$ ). Active casp6 immunostaining is also detected on neurites (Fig. $3 A$ ). In mice expressing C6R mhtt, a low level of immunopositive active casp6-stained neurons are observed at 12 and 18 months of age (Fig. $3 A m-A x$ ). Correlating with the immunohistochemical results, a significant increase in casp6 activity in protein lysates from YAC128 cortex is observed compared with WT and C6R at 12 and 18 months of age (Fig. 3B: 12 months, ANOVA, $p<0.013$; WT vs YAC128, $p<0.05$; C6R vs YAC128, $p<$ $0.05, n=15$; Fig. $3 C$ : 18 months, ANOVA, $p=0.002$; WT vs YAC8, $p<0.01$; C6R vsYAC128, $p<0.05 ; n=9$ ).

These results demonstrate that, similar to human HD brain, striatal activation of casp6 is an early event in the YAC128 model and suggest that cortical upregulation of casp6 occurs later than striatal activation in this animal model of HD. Furthermore, inhibiting casp6 cleavage of mhtt alters casp6 activation patterns in vivo, suggesting that $\mathrm{C} 6 \mathrm{R}$ mhtt protects against neurodegeneration by interfering with activation of casp6 and supporting the hypothesis that cleavage at amino acid 586 in mhtt is critical for activation of cell-death pathways in HD.

Severity of disease correlates with caspase-6 activity levels We have demonstrated previously that onset and progression of HD is modulated by levels of mhtt in the YAC128 mouse models (Fig. 4A) (Graham et al., 2006b). To determine the influence of disease stage on the activation of casp6 in the YAC128 model, we next assessed casp6 activity in YAC128 line HD54, our lowest mhtt expressing line that demonstrates a later onset and less severe phenotype compared with YAC128-HD53.

In contrast to the YAC128 line HD53, at 3 months of age, there is no difference in casp6 activity in the striatum of WT and HD54 mice $(p=0.34, n=8)$ (Fig. $4 B$ ). A one-way ANOVA linear trend post hoc test reveals a significant trend between WT, HD54, and HD53 for casp6 activity (ANOVA, $p=0.105$, post hoc for linear trend: slope of $0.065, r^{2}=0.1493, p=0.03$ ).

If activation of casp6 is a critical event in HD, we would expect other HD mouse models to similarly demonstrate enhanced casp6 activation. Therefore, we assessed casp6 activity in the fulllength BACHD model. At 12 months of age, there is a significant increase in casp6 activity in both striatum and cortex of BACHD mice ( $p=0.003$ and $p=0.02$ respectively, $n=4)$ (Fig. $4 C$ ), consistent with our findings in the YAC128 animals.

\section{Alterations in caspase- 3 are not observed early in the pathogenesis of HD}

To determine whether the early enhanced activation of casp6 observed in human HD brain is generalizable to other caspases or is specific for casp6, we assessed caspase-3 (casp3) activation in human HD brain and in the YAC128 model. In grade $0-1$ human HD striatum, no difference was observed in the proform levels of casp3 compared with age-matched control tissue (Fig. 5A). In grade 3-4 HD striatum, there is a trend toward decreased p34 proform levels of casp3 in HD compared with control tissue $(n=$ 6 control, $n=9 \mathrm{HD}, p=0.06$ ) (Fig. $5 B$ ). In contrast, in grade 3-4 HD frontal cortex, a clear increase in p34 proform casp3 levels is observed compared with control tissue ( $p=0.02, n=3$ control, $n=5 \mathrm{HD}$ ) (Fig. $5 C$ ). The active p20 casp3 fragments were not detected in control or HD striatal or frontal cortex tissue.

To determine whether alterations in casp3 are observed in the YAC128 model, perfused coronal sections of WT and YAC128 mice were stained with three separate antibodies specific for the active form of casp3 at 3 and 12 months of age $(n=3)$. No 

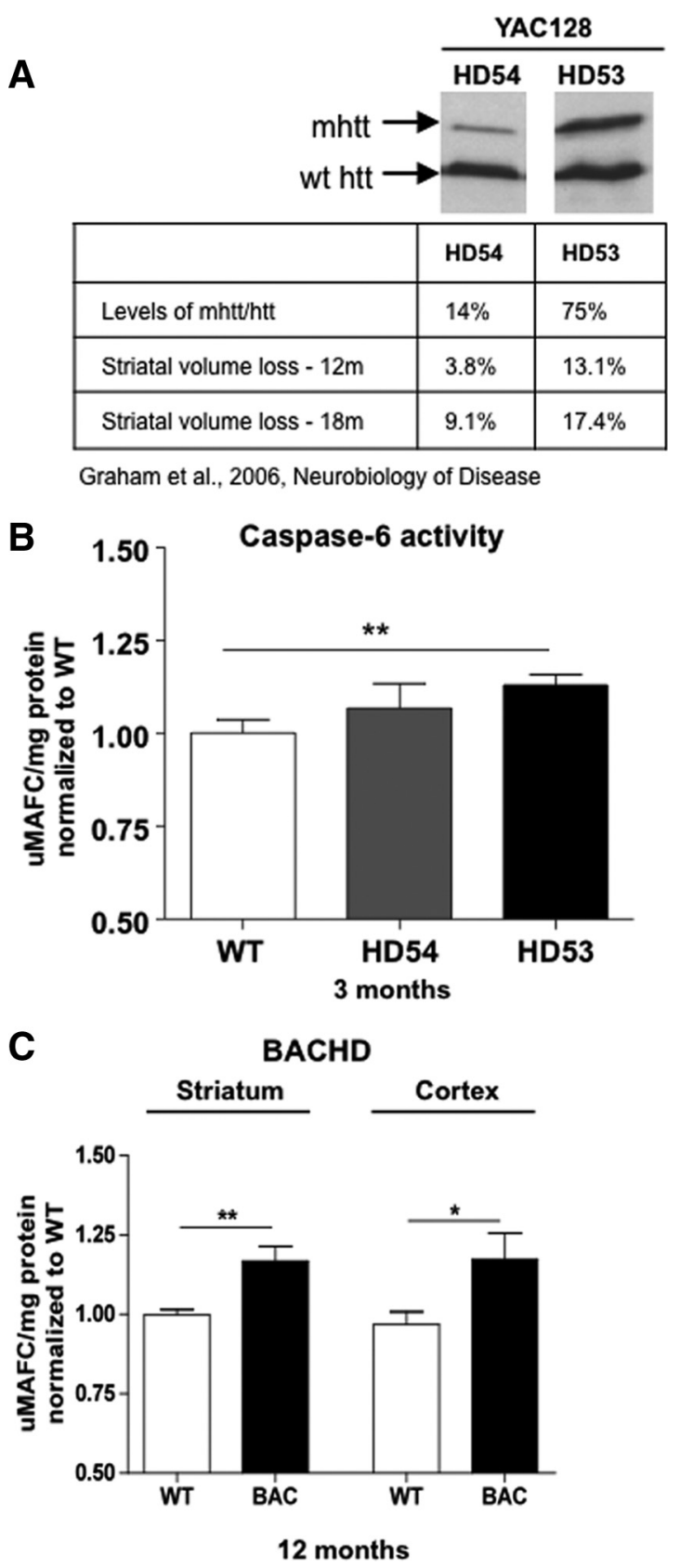

Figure 4. Disease severity correlates with striatum and cortex caspase-6 activity in mouse models of HD. $A$, Onset and progression of HD is modulated by expression levels of mhtt in the YAC128 mouse models (Graham et al., 2006b). Western blot probed with N-terminal BKP1 htt antibody. $\boldsymbol{B}$, At 3 months of age, no difference in casp6 activity is observed between WT or HD54 striatum ( $p=0.34$ ). One-way ANOVA linear trend post hoc test reveals a significant trend between WT, YAC128 -HD54, and YAC128-HD53 for casp6 activity (ANOVA, $p=0.105$, post hoc for linear trend: slope of $0.065, r^{2}=0.1493, p=0.03$ ). C, Assessment of casp6 activity in brain tissue from the BACHD model at 12 months of age reveals a significant increase in casp6 activity in both striatum and cortex of BACHD mice compared with WT ( $p=0.003$ and $p=$ 0.02 , respectively). casp6 activity measurements are \pm SEM. ${ }^{*} p<0.05$; ${ }^{* *} p<0.01$.

immunopositive staining was observed at either of these time points in striatum (Fig. 5D) or cortex in WT or YAC128 brain sections. Correlating with the immunohistochemical data, no difference in casp 3 activity was observed in WT versus YAC128 striatum at 3 and 12 months of age ( 3 months, $p=0.11, n=10$; 12 months, $p=0.62, n=12$ ) (Fig. $5 E$ ) or cortex (3 months, $p=$ $0.87, n=9 ; 12$ months, $p=0.15, n=12$ ) (data not shown). Immunopositive active casp3 was detected in the corpus callo- sum of both WT and YAC128 brain slices, but no difference in the extent of staining was observed between genotypes (Fig. $5 D$ ). The casp3-positive immunostaining did not colocalize with cresyl violet-stained cells and may represent lysosome or autophagosome-like structures as has been described previously (Stadelmann et al., 1999).

Casp2 activity was also assessed in WT and YAC128 striatum and cortex. At 3 months of age, no difference in casp2 activity is observed between genotypes in either the striatum $(p=0.54)$ or $\operatorname{cortex}(p=0.43)$.

\section{Excitotoxic stress influences caspase- 6 activation}

Caspase activation occurs early in HD brain, but how this correlates with other early changes leading to excitotoxicity is not known. We have demonstrated previously enhanced susceptibility to excitotoxic stress in neonatal MSNs from multiple YAC lines (Zeron et al., 2002; Graham et al., 2006a,b, 2009; Milnerwood et al., 2010), underscoring the early nature of excitotoxic stress in the pathogenesis of HD.

To determine the relationship between casp6 activation and excitotoxic death of striatal MSNs, we used a neo-epitope antibody specific for the active form of casp6. We labeled $9 \mathrm{~d}$ in vitro primary cultured MSNs (WT, YAC128) by immunocytochemistry at 4 and $6 \mathrm{~h}$ after NMDA challenge. In MSNs expressing mhtt, a significant increase in the percentage of neurons immunopositive for active casp6 is observed at $6 \mathrm{~h}(p=0.04)$ after NMDA treatment and a trend was observed at $4 \mathrm{~h}(p=0.07)(n=4 \mathrm{WT}$ and $n=6$ YAC128 separate cultures) (Fig. $6 A, B$ ).

To verify the casp6 immunofluorescence data, we next assessed casp6 mRNA levels and casp6 activity in MSNs from WT and YAC128 after NMDA treatment. A significant increase in levels of casp6 mRNA and casp6 activity is observed in neurons expressing mhtt compared with WT $3.5 \mathrm{~h}$ after NMDA application (casp6 mRNA levels, WT vs YAC128, $p=0.015, n=3$; casp6 activity, WT vs YAC128, $p=0.011, n=10$ ) (Fig. $6 C$ ). Saturating concentrations of NMDA do trigger specific activation of some caspases, which include casp9 and casp3 (Zeron et al., 2002, 2004), in MSNs expressing mhtt compared with WT MSNs. Caspase-8 (IETDase) activity is not increased in this paradigm (Zeron et al., 2004).

We have demonstrated previously that, in contrast to YAC128 MSNs, C6R MSNs are resistant to NMDAR-induced neurotoxicity (Graham et al., 2006a; Milnerwood et al., 2010). To investigate the mechanisms underlying this differential susceptibility to excitotoxic cell death, we compared casp6 activity in MSNs containing C6R mhtt after NMDA treatment with YAC128. In contrast to YAC128 MSNs, no increase in casp6 activity is observed in C6R MSNs $3.5 \mathrm{~h}$ after NMDA treatment (ANOVA, $p=0.04$; WT vs C6R, $p>0.05$; WT vs YAC128, $p<0.05, n=7$ ) (Fig. $6 C$ ).

If activation of casp6 is necessary for NMDAR-mediated cell death in MSNs expressing mhtt, we hypothesized that a casp6 inhibitor would rescue primary MSNs in this paradigm. Therefore, we pretreated MSNs from WT and YAC128 striata with the casp6 peptide inhibitor z-VEID-fmk before NMDA treatment. A significant decrease in NMDAR-mediated apoptotic cell death was observed in MSNs pretreated with z-VEID-fmk from WT (ANOVA, $p=0.014$; percentage apoptotic neurons in NMDA vs NMDA plus casp6 inhibitor, $p<0.05, n=3$ ) and YAC128 striata (ANOVA, $p=0.0001$; percent apoptotic neurons in BSS vs NMDA, $p<0.001$; NMDA vs NMDA plus casp6 inhibitor, $p<$ $0.001, n=3$ ) (Fig. $6 D$ ). We also pretreated MSNs from WT and YAC128 striata with the caspase-3 peptide inhibitor z-DEVDfmk before NMDA treatment. A significant decrease in NMDAR- 


\section{Human HD- Caspase-3}

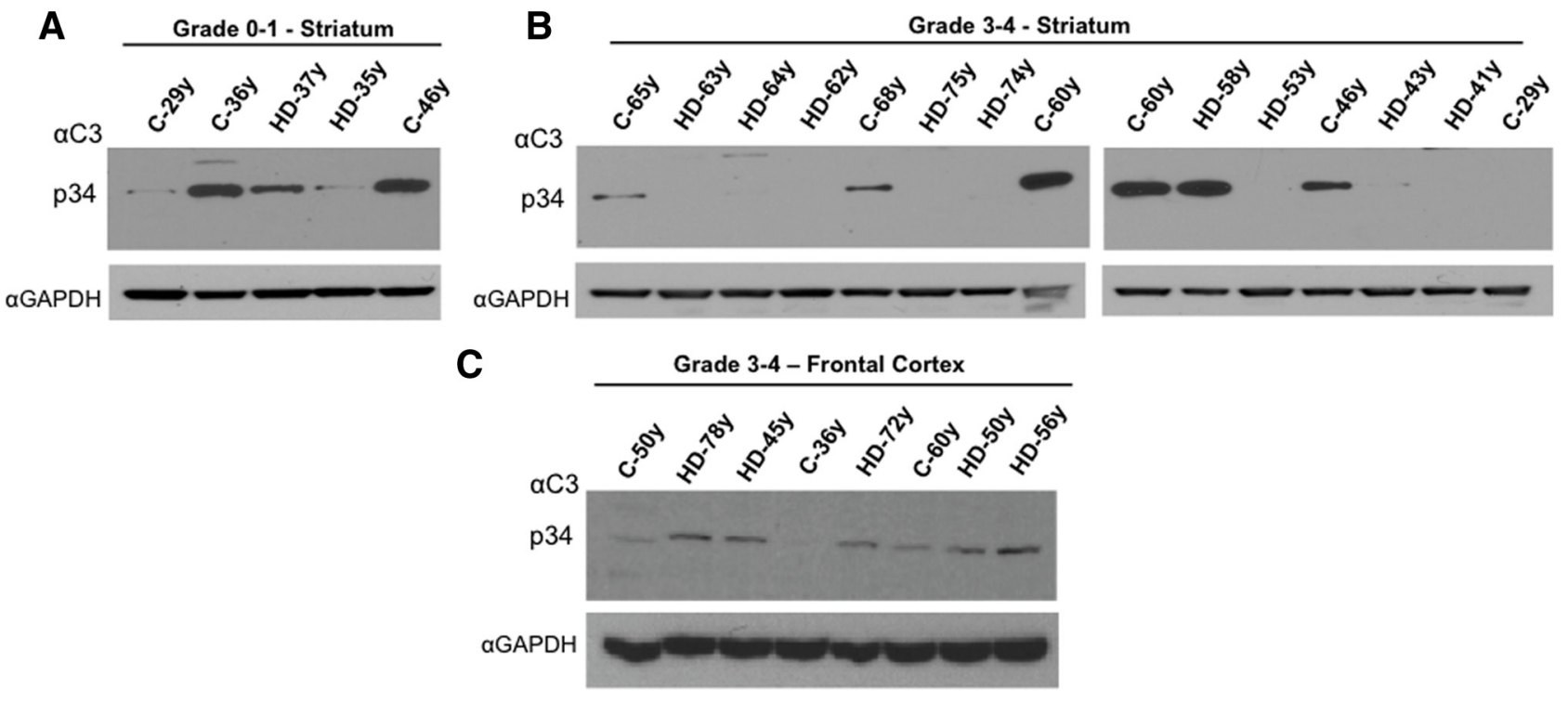

YAC128 - Caspase-3
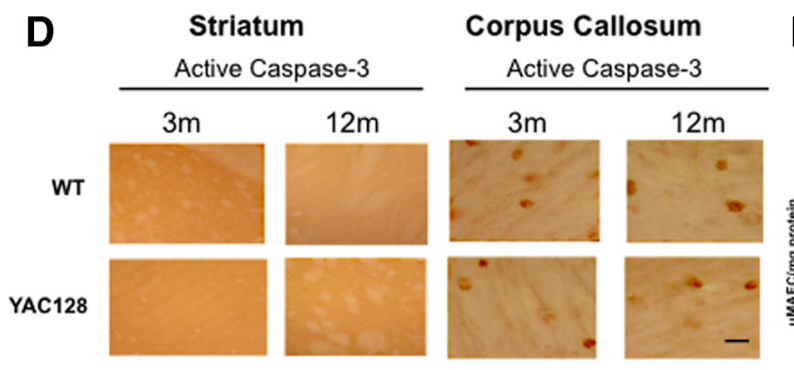

E

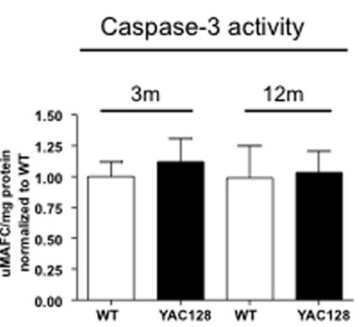

Figure 5. Activation of caspase- 3 is not observed early in the pathogenesis of HD. $A$, No difference is observed in proform levels of casp3 in grade $0-1$ human HD striatum compared with age-matched control tissue. $\boldsymbol{B}$, In grade 3-4 HD striatum, there is a trend toward decreased $\mathrm{p} 34$ proform levels of casp 3 compared with control tissue $(p=0.06)$. $\boldsymbol{C}$, In grade $3-4 \mathrm{HD}$ frontal cortex, an increase in p34 proform casp3 levels is observed compared with control tissue $(p=0.02)$. The active $p 20$ casp3 fragments were not detected in control or HD striatal or frontal cortex tissue. $D$, No immunopositive active casp3 staining is observed in the striatum of WT or YAC128 brain. Immunopositive active casp3 staining is detected in the corpus callosum of both WT and YAC128 brain slices, but no difference in the extent of staining is observed between genotypes. $E$, No difference in casp3 activity is observed in WT versus YAC128 striatum at 3 or 12 months of age ( 3 months, $p=$ $0.11 ; 12$ months, $p=0.62$ ). Mean measurements and densitometric ratios of casp3p34/GAPDH and casp3 activity measurements are \pm SEM. ${ }^{*} p<0.05$. Magnification, $100 \times$. Scale bar, $10 \mu \mathrm{m}$.

mediated apoptotic cell death was observed in MSNs pretreated with $z$-DEVD-fmk from WT (ANOVA, $p=0.002$; percentage apoptotic neurons in NMDA vs NMDA plus casp3 inhibitor, $p<$ 0.01 ) and YAC128 striata (ANOVA, $p=0.0001$; percentage apoptotic neurons in BSS vs NMDA, $p<0.001$; NMDA vs NMDA plus casp3 inhibitor, $p<0.001, n=3$ ) (Fig. $6 E$ ).

\section{Discussion}

In this study, our goal was to investigate the patterns of activation of casp6 in an effort to investigate its potential role in the pathogenesis of HD. Our results demonstrate that active casp6 is present in early-grade and presymptomatic HD brain. Significantly, the active casp6 observed in early-stage HD tissue is observed at a time when no active casp3 is detected. Intriguingly, we found that active casp6 levels correlate with CAG size in human HD brain and inversely correlate with age of onset. These data suggest that the expanded polyglutamine tract in mhtt influences casp6 activation levels and support a role for casp6 in the early selectivity of vulnerable striatal neurons in HD.

Enhanced levels of active casp6 and increased casp6 activity are also observed in brain tissue from two separate, symptomatic $\mathrm{HD}$ mouse models. C6R mice do not demonstrate increased casp6 activation, suggesting that the 586 aa htt fragment may be part of a forward amplification cycle of casp 6 activation. In the absence of this fragment, as in the C6R mice, we now show that activation of casp6 is muted.

A major question is, what stimulates casp6 activation in HD? Here we show that NMDAR-mediated excitotoxicity triggers activation of casp6 in mhtt-expressing MSNs isolated from YAC128 striata at birth. This may provide an explanation for the early activation of casp6 in vivo and highlights links between casp6 activation and excitotoxicity in the pathogenesis of HD. The underlying reason(s) for excitotoxicity in HD may be several-fold and include increases in extracellular glutamate attributable to altered expression and/or function of glutamate transporters (Faideau et al., 2010; Huang et al., 2010) and mislocalization and altered signaling of extrasynaptic NMDARs (Milnerwood et al., 2010). Recent evidence points to these events as being dependent on mhtt cleavage at amino acid 586 (Graham et al., 2006a; Milnerwood et al., 2010).

Casp6 activation occurs normally as part of the aging process with small increases at 9 months of age in the striatum and by 1 year of age in the cortex of WT mice, consistent with previous 
A

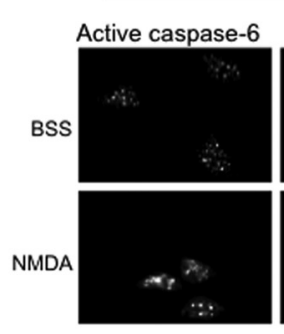

WT
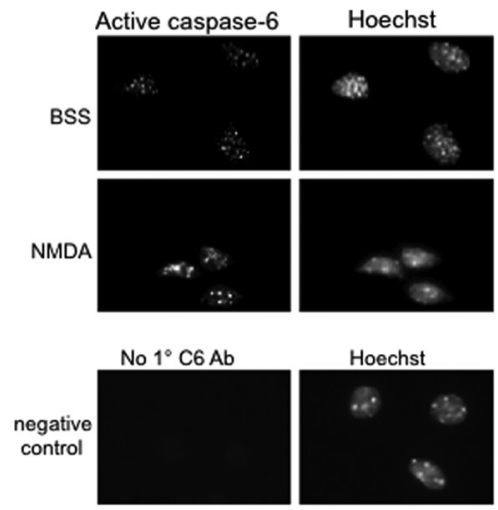

D

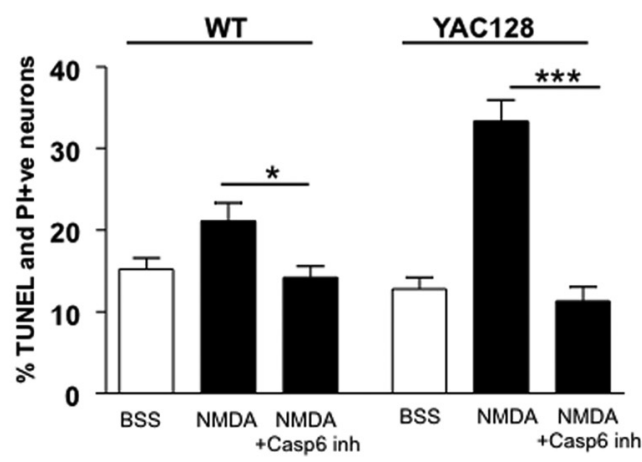

B
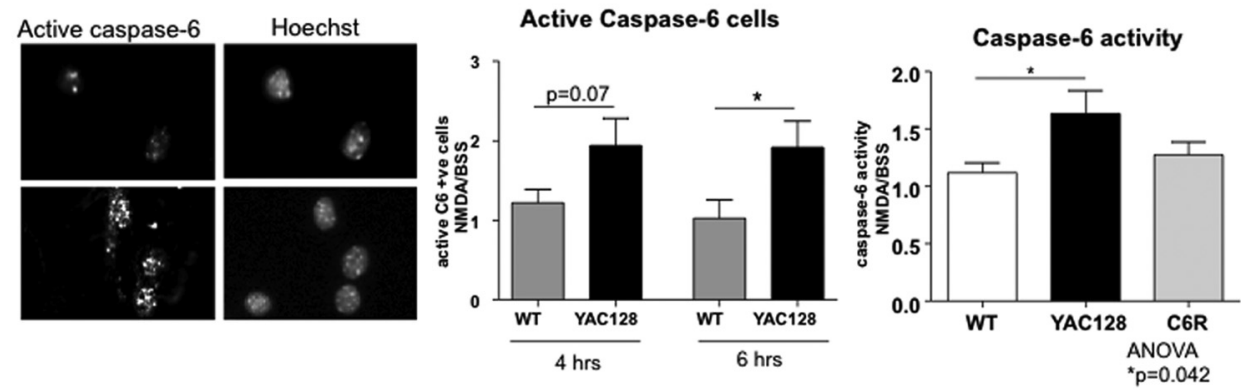

E

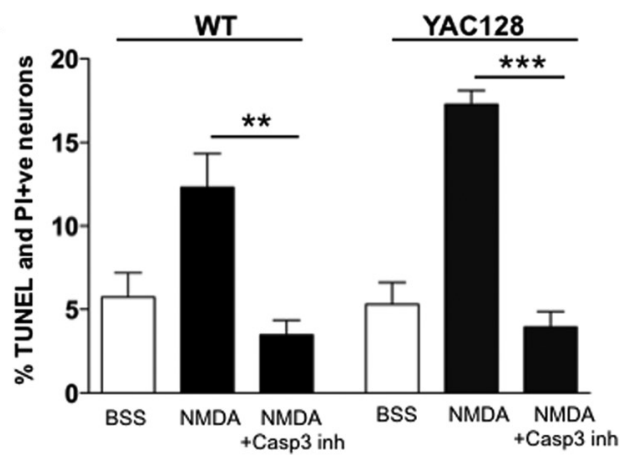

Figure 6. NMDA-mediated excitotoxic stress triggers caspase-6 activation. $A, B$, Primary MSNs were double labeled with active casp6 neo-epitope antibody and Hoechst. In YAC128 MSNs, the percentage of MSNs with active casp6 immunoreactivity above background increased after NMDA treatment compared with WT at $6 \mathrm{~h}(p<0.05)$ and a trend increased at $4 \mathrm{~h}(p=0.07)$. C, A significant increase in casp6 activity is observed in neurons expressing mhtt compared with WT $3.5 \mathrm{~h}$ after NMDA application ( $t$ test, WT vs YAC128: $p=0.015$ and $p=0.011$, respectively). No increase in casp6 activity is observed in (6R MSNs after NMDA treatment (ANOVA, $p=0.04$; WT vs (6R, $p>0.05$; WT vs YAC128, $p<0.05$ ). D, A significant decrease in NMDAR-mediated apoptotic cell death is observed in MSNs pretreated with z-VEID-fmk from WT (ANOVA, $p=0.014$; percentage apoptotic neurons in NMDA vs NMDA plus casp6 inhibitor, $p<0.05$ ) and YAC128 (ANOVA, $p=$ 0.0001; percentage apoptotic neurons in BSS vs NMDA, $p<0.001$; NMDA vs NMDA plus casp6 inhibitor, $p<0.001$ ) striata. $\boldsymbol{E}$, A significant decrease in NMDAR-mediated apoptotic cell death is observed in MSNs pretreated with z-DEVD-fmk from WT (ANOVA, $p=0.002$; percentage apoptotic neurons in NMDA vs NMDA plus casp3 inhibitor, $p<0.01$ ) and YAC128 (ANOVA, $p=0.0001$; percentage apoptotic neurons in BSS vs NMDA, $p<0.001$; NMDA vs NMDA plus casp3 inhibitor, $p<0.001$ ) striata. Relative casp6 activity measurements are \pm SD. Mean percentage apoptotic cell death is given \pm SD. ${ }^{*} p<0.05 ;{ }^{* * *} p<0.001$.

studies (Jiang et al., 2001; Albrecht et al., 2007). However, in HD, this process is significantly amplified and accelerated in both striatum and cortex. The pattern of activation parallels the early selective neuronal loss with predominant effects in the striatum. Active casp6 is detected in the neurons and neurites of the cortex of YAC128 mice by 9 months of age, but this occurs subsequent to striatal activation.

CAG length significantly influences onset and clinical features of HD in mouse models and affected humans (Hodgson et al., 1999; Zeron et al., 2002; Langbehn et al., 2004). Intriguingly, similar to the correlation between CAG repeat length and mitochondrial ADP uptake (Seong et al., 2005) and body weight (Aziz et al., 2008), we now demonstrate that active casp6 levels also correlate with CAG size and inversely with age of onset in HD brain. This correlation with CAG size highlights another example of longer polyglutamine stretches associating with a more severe phenotype.

A major unanswered question is whether casp6 is the protease responsible for cleavage of htt at amino acid 586. We have demonstrated previously in vitro that casp6 cleaves htt at the IVLD 586 aa site (Wellington et al., 2000; Graham et al., 2006a; Warby et al., 2008). Caspases cleave with remarkable specificity at a small subset of aspartic acid residues within only a discrete and highly limited subset of cellular polypeptides (Thornberry et al., 1997, 2000). Studies with peptide-based and macromolecular inhibi- tors support the IVLD site as an optimal tetrapeptide recognition motif for casp6 (Thornberry et al., 1997). The activation of casp6 in HD brain supports the hypothesis that casp6 cleaves htt at the IVLD site in vivo. However, this is not definitive, and studies using mice deficient in casp6 are required to address this question.

The finding that casp6 activation occurs in the YAC128 model and not in the C6R mice suggests that the 586 aa mhtt fragment may play a crucial role in the amplification of casp6 in HD. Cleavage products of caspases have been shown previously to be part of an amplification cycle. Stress-induced generation of caspasecleaved proteolytic fragments triggers toxicity and amplifies the cell-death response. For example, caspase-dependent cleavage of CDC25A generates an active fragment that activates cyclindependent kinase 2 during apoptosis (Mazars et al., 2009), and casp6-cleavage of nuclear factor- $\kappa \mathrm{B}(\mathrm{NF}-\kappa \mathrm{B})$ generates a dominant-negative inhibitor of $\mathrm{NF}-\kappa \mathrm{B}$, thereby promoting apoptosis (Levkau et al., 1999).

Indirect evidence in favor of the 586 aa htt fragment being involved in an amplification loop for casp6 activation in HD includes the observation that active casp6 and the 586 aa htt fragments colocalize in the nucleus (Warby et al., 2008). Several studies have shown that nuclear accumulation of htt fragments is associated with increased toxicity (Hackam et al., 1998; Slow et al., 2003; Van Raamsdonk et al., 2005; Graham et al., 2006b), and, 
in YAC128 mice, nuclear localization of htt occurs earliest and to the greatest extent in the striatum, correlating with the neuropathology observed (Van Raamsdonk et al., 2005). In contrast, nuclear accumulation of htt is delayed in the C6R mice (Graham et al., 2006a), showing that blocking formation of the casp6 mhtt fragment ameliorates the neuropathological and behavioral phenotype in the C6R mice.

Early activation of casp6 in HD, and the absence of active casp6 in the C6R mice, raises the question as to whether cleavage of other casp 6 substrates could contribute to the pathogenesis of HD. In other words, could the absence of cleavage of particular casp6 substrates in the C6R mice contribute to the neuroprotective phenotype observed in these mice? Interestingly, a number of other casp6 substrates have been implicated in HD, including CREB (cAMP response element-binding protein) binding protein (CBP) and NF- $\kappa$ B (Qin et al., 1999; Steffan et al., 2000; Khoshnan et al., 2004; Jiang et al., 2006). casp6 selectively cleaves CBP (Rouaux et al., 2004), suggesting that casp6 activation may contribute to the altered gene transcription observed in HD. Transcriptional repression of specific genes is observed in HD (Steffan et al., 2000; Hodges et al., 2006; Jiang et al., 2006). Potential mechanisms include altered binding of mhtt and CBP, inactivation of CBP through casp6 cleavage, and/or sequestration of CBP in inclusions (Steffan et al., 2000; Jiang et al., 2006). Interestingly, casp6-mediated cleavage of NF- $\kappa \mathrm{B}$ generates a transcriptionally inactive p65 molecule that acts as a dominantnegative inhibitor of NF- $\kappa \mathrm{B}$ and promotes apoptosis. In contrast, casp6-resistant p65 protects cells from apoptosis (Levkau et al., 1999). Therefore, other substrates that are cleaved by casp 6 could play a role in $\mathrm{HD}$, and it is important to define all potential casp6 substrates in human brain to explore their role in HD.

A very important question then is, what initiates casp6 activation in HD? Our previous observations in C6R mice that amelioration of the behavioral and neuronal deficits is associated with protection against excitotoxic stress (Graham et al., 2006a; Milnerwood et al., 2010) support the hypothesis of mhtt-mediated alterations of excitotoxicity as an important contributor to caspase activation. Here we demonstrate that NMDAR-mediated excitotoxicity activates casp6 in neurons expressing caspasecleavable mhtt but not C6R mhtt. These findings are mirrored by decreased activation of casp6 in the brains of C6R mice. These data strongly support enhanced excitotoxicity in HD (Beal et al., 1991; Li et al., 2004; Graham et al., 2006a, 2009; Guidetti et al., 2006) as an early event contributing to casp6 activation. Recent studies provide additional evidence and demonstrate that increased extrasynaptic NMDAR-induced currents and signaling is a critical underlying mechanism in the pathogenesis of HD (Okamoto et al., 2009; Milnerwood et al., 2010). Of note is the finding that increased extrasynaptic NMDAR activity requires casp6 cleavage of htt. Electrophysiological investigation of the C6R mice demonstrates that C6R MSNs are remarkably similar to MSNs overexpressing wild-type htt (YAC18) and WT MSNs and significantly different from YAC128 MSNs (Milnerwood et al., 2010). The data suggest that increased extrasynaptic NMDAR activation is intimately linked to generation of the 586 aa fragment of htt and that caspase- 6 cleavage of mhtt is necessary for increased extrasynaptic NMDA current $\left(\mathrm{Ex}-I_{\mathrm{NMDA}}\right)$, leading to behavioral deficits, excitotoxicity, and neurodegeneration.

Consistent with a role for casp6 in excitotoxicity, we find that inhibiting casp6 protects MSNs from NMDAR-mediated cell death. In addition, we also demonstrate that inhibition of casp3 similarly protects MSNs against excitotoxic cell death. It may be expected that inhibition of a downstream executioner caspase such as casp3 would provide protection against cell death. It is important to note however that casp 6 can activate casp3 both in vitro and ex vivo (Liu et al., 1996; Xanthoudakis et al., 1999; Allsopp et al., 2000), and activation of casp6 is observed before casp 3 in in vivo excitotoxic models (Ferrer et al., 2000; Henshall et al., 2002). This evidence, and the data demonstrating activation of casp6 in presymptomatic $\mathrm{HD}$ and AD brains, suggests that casp6 can function upstream of casp3 and may influence its activation.

The increase in casp6 mRNA after NMDA treatment may be the result of NMDAR-mediated increases in p53. Glutamateinduced neurotoxicity leads to accumulation of p53 (Xiang et al., 1998; Culmsee et al., 2001; Liang et al., 2005), and downregulation of p53 protects neurons against excitotoxicity (Morrison et al., 1996, 2003; Culmsee et al., 2001). Induction of p53 has been shown to directly induce casp6 expression through a response element within the third intron of the gene (MacLachlan and El-Deiry, 2002).

Interestingly, casp3 and casp6 have remarkably different caspase activation patterns in HD brain. We did not detect active casp3 or alterations in the proform of casp3 in early HD, but we did observe a decrease in the proform of casp3 in late-stage HD striatum. Indeed, active casp 3 has been observed in degenerating astrocytes in the caudate of patients with advanced HD (Hermel et al., 2004). These data show that casp3 is not involved early in the pathogenesis of HD.

Casp6 cleavage of substrates and casp6 activation is also present in $\mathrm{AD}$. Activation of casp6 is an early event in human $\mathrm{AD}$ brain (Pompl et al., 2003; Albrecht et al., 2007), and, similar to htt, APP is cleaved by caspases resulting in elevated levels of amyloid- $\beta$ peptide (Gervais et al., 1999; Tesco et al., 2007). Cleavage of APP occurs at the Asp664 casp6 site in vivo (Banwait et al., 2008), and inhibiting cleavage at this site provides some rescue from the AD phenotype in a mouse model (Galvan et al., 2006, 2008; Saganich et al., 2006; Harris et al., 2010; Zhang et al., 2010). Cleavage of APP generates an N-terminal APP fragment that is a death ligand for death-receptor 6 (DR6), and activation of DR6 triggers casp6 activation and axonal degeneration (Nikolaev et al., 2009). The evidence implicating casp6 in AD and HD suggests that casp 6 may be a crucial enzyme underlying neurodegeneration in both diseases.

The results of these studies support a critical role for casp6 early in HD and demonstrate that inhibiting cleavage of a caspase substrate can influence caspase activation patterns in vivo. These data suggest that specific mhtt fragments are required to initiate a toxic amplification cycle that contributes to neuronal dysfunction and the neuropathological abnormalities in HD. Furthermore, we demonstrate a strong relationship between casp6 and excitotoxicity, which supports therapeutic approaches to identify inhibitors of casp6 and/or excitotoxic stress as ways to influence the pathogenesis of HD.

\section{References}

Albrecht S, Bourdeau M, Bennett D, Mufson EJ, Bhattacharjee M, LeBlanc AC (2007) Activation of caspase-6 in aging and mild cognitive impairment. Am J Pathol 170:1200-1209.

Allsopp TE, McLuckie J, Kerr LE, Macleod M, Sharkey J, Kelly JS (2000) Caspase 6 activity initiates caspase 3 activation in cerebellar granule cell apoptosis. Cell Death Differ 7:984-993.

Andrew SE, Goldberg YP, Theilmann J, Zeisler J, Hayden MR (1994) A CCG repeat polymorphism adjacent to the CAG repeat in the Huntington disease gene: implications for diagnostic accuracy and predictive testing. Hum Mol Genet 3:65-67.

Aziz NA, van der Burg JM, Landwehrmeyer GB, Brundin P, Stijnen T, Roos 
RA; EHDI Study Group (2008) Weight loss in Huntington disease increases with higher CAG repeat number. Neurology 71:1506-1513.

Banwait S, Galvan V, Zhang J, Gorostiza OF, Ataie M, Huang W, Crippen D, Koo EH, Bredesen DE (2008) C-terminal cleavage of the amyloid-beta protein precursor at Asp664: a switch associated with Alzheimer's disease. J Alzheimers Dis 13:1-16.

Beal MF, Ferrante RJ, Swartz KJ, Kowall NW (1991) Chronic quinolinic acid lesions in rats closely resemble Huntington's disease. J Neurosci 11:1649-1659.

Culmsee C, Zhu X, Yu QS, Chan SL, Camandola S, Guo Z, Greig NH, Mattson MP (2001) A synthetic inhibitor of p53 protects neurons against death induced by ischemic and excitotoxic insults, and amyloid beta-peptide. J Neurochem 77:220-228.

Faideau M, Kim J, Cormier K, Gilmore R, Welch M, Auregan G, Dufour N, Guillermier M, Brouillet E, Hantraye P, Déglon N, Ferrante RJ, Bonvento G (2010) In vivo expression of polyglutamine-expanded huntingtin by mouse striatal astrocytes impairs glutamate transport: a correlation with Huntington's disease subjects. Hum Mol Genet 19:3053-3067.

Ferrer I, López E, Blanco R, Rivera R, Krupinski J, Martí E (2000) Differential c-Fos and caspase expression following kainic acid excitotoxicity. Acta Neuropathol 99:245-256.

Galvan V, Gorostiza OF, Banwait S, Ataie M, Logvinova AV, Sitaraman S, Carlson E, Sagi SA, Chevallier N, Jin K, Greenberg DA, Bredesen DE (2006) Reversal of Alzheimer's-like pathology and behavior in human APP transgenic mice by mutation of Asp664. Proc Natl Acad Sci U S A 103:7130-7135.

Galvan V, Zhang J, Gorostiza OF, Banwait S, Huang W, Ataie M, Tang H, Bredesen DE (2008) Long-term prevention of Alzheimer's disease-like behavioral deficits in PDAPP mice carrying a mutation in Asp664. Behav Brain Res 191:246-255.

Garden GA, Libby RT, Fu YH, Kinoshita Y, Huang J, Possin DE, Smith AC, Martinez RA, Fine GC, Grote SK, Ware CB, Einum DD, Morrison RS, Ptacek LJ, Sopher BL, La Spada AR (2002) Polyglutamine-expanded ataxin-7 promotes non-cell-autonomous purkinje cell degeneration and displays proteolytic cleavage in ataxic transgenic mice. J Neurosci 22:4897-4905.

Gervais FG, Xu D, Robertson GS, Vaillancourt JP, Zhu Y, Huang J, LeBlanc A, Smith D, Rigby M, Shearman MS, Clarke EE, Zheng H, Van Der Ploeg LH, Ruffolo SC, Thornberry NA, Xanthoudakis S, Zamboni RJ, Roy S, Nicholson DW (1999) Involvement of caspases in proteolytic cleavage of Alzheimer's amyloid-beta precursor protein and amyloidogenic A beta peptide formation. Cell 97:395-406.

Graham RK, Deng Y, Slow EJ, Haigh B, Bissada N, Lu G, Pearson J, Shehadeh J, Bertram L, Murphy Z, Warby SC, Doty CN, Roy S, Wellington CL, Leavitt BR, Raymond LA, Nicholson DW, Hayden MR (2006a) Cleavage at the caspase- 6 site is required for neuronal dysfunction and degeneration due to mutant huntingtin. Cell 125:1179-1191.

Graham RK, Slow EJ, Deng Y, Bissada N, Lu G, Pearson J, Shehadeh J, Leavitt BR, Raymond LA, Hayden MR (2006b) Levels of mutant huntingtin influence the phenotypic severity of Huntington disease in YAC128 mouse models. Neurobiol Dis 21:444-455.

Graham RK, Pouladi MA, Joshi P, Lu G, Deng Y, Wu NP, Figueroa BE, Metzler M, André VM, Slow EJ, Raymond L, Friedlander R, Levine MS, Leavitt BR, Hayden MR (2009) Differential susceptibility to excitotoxic stress in YAC128 mouse models of Huntington disease between initiation and progression of disease. J Neurosci 29:2193-2204.

Gray M, Shirasaki DI, Cepeda C, André VM, Wilburn B, Lu XH, Tao J, Yamazaki I, Li SH, Sun YE, Li XJ, Levine MS, Yang XW (2008) Fulllength human mutant huntingtin with a stable polyglutamine repeat can elicit progressive and selective neuropathogenesis in BACHD mice. J Neurosci 28:6182-6195.

Guidetti P, Luthi-Carter RE, Augood SJ, Schwarcz R (2004) Neostriatal and cortical quinolinate levels are increased in early grade Huntington's disease. Neurobiol Dis 17:455-461.

Guidetti P, Bates GP, Graham RK, Hayden MR, Leavitt BR, MacDonald ME, Slow EJ, Wheeler VC, Woodman B, Schwarcz R (2006) Elevated brain 3-hydroxykynurenine and quinolinate levels in Huntington disease mice. Neurobiol Dis 23:190-197.

Guo H, Albrecht S, Bourdeau M, Petzke T, Bergeron C, LeBlanc AC (2004) Active caspase- 6 and caspase-6-cleaved tau in neuropil threads, neuritic plaques, and neurofibrillary tangles of Alzheimer's disease. Am J Pathol 165:523-531.
Hackam AS, Singaraja R, Wellington CL, Metzler M, McCutcheon K, Zhang T, Kalchman M, Hayden MR (1998) The influence of huntingtin protein size on nuclear localization and cellular toxicity. J Cell Biol 141: 1097-1105.

Harris JA, Devidze N, Halabisky B, Lo I, Thwin MT, Yu GQ, Bredesen DE, Masliah E, Mucke L (2010) Many neuronal and behavioral impairments in transgenic mouse models of Alzheimer's disease are independent of caspase cleavage of the amyloid precursor protein. J Neurosci 30:372-381.

Henshall DC, Skradski SL, Meller R, Araki T, Minami M, Schindler CK, Lan JQ, Bonislawski DP, Simon RP (2002) Expression and differential processing of caspases 6 and 7 in relation to specific epileptiform EEG patterns following limbic seizures. Neurobiol Dis 10:71-87.

Hermel E, Gafni J, Propp SS, Leavitt BR, Wellington CL, Young JE, Hackam AS, Logvinova AV, Peel AL, Chen SF, Hook V, Singaraja R, Krajewski S, Goldsmith PC, Ellerby HM, Hayden MR, Bredesen DE, Ellerby LM (2004) Specific caspase interactions and amplification are involved in selective neuronal vulnerability in Huntington's disease. Cell Death Differ 11:424-438.

Hodges A, Strand AD, Aragaki AK, Kuhn A, Sengstag T, Hughes G, Elliston LA, Hartog C, Goldstein DR, Thu D, Hollingsworth ZR, Collin F, Synek B, Holmans PA, Young AB, Wexler NS, Delorenzi M, Kooperberg C, Augood SJ, Faull RL, Olson JM, Jones L, Luthi-Carter R (2006) Regional and cellular gene expression changes in human Huntington's disease brain. Hum Mol Genet 15:965-977.

Hodgson JG, Agopyan N, Gutekunst CA, Leavitt BR, LePiane F, Singaraja R, Smith DJ, Bissada N, McCutcheon K, Nasir J, Jamot L, Li XJ, Stevens ME, Rosemond E, Roder JC, Phillips AG, Rubin EM, Hersch SM, Hayden MR (1999) A YAC mouse model for Huntington's disease with full- length mutant huntingtin, cytoplasmic toxicity, and selective striatal neurodegeneration. Neuron 23:181-192.

Huang K, Kang MH, Askew C, Kang R, Sanders SS, Wan J, Davis NG, Hayden MR (2010) Palmitoylation and function of Glial Glutamate Transporter-1 is reduced in the YAC128 mouse model of Huntington disease. Neurobiol Dis 40:207-215.

Jiang CH, Tsien JZ, Schultz PG, Hu Y (2001) The effects of aging on gene expression in the hypothalamus and cortex of mice. Proc Natl Acad Sci U S A 98:1930-1934.

Jiang H, Poirier MA, Liang Y, Pei Z, Weiskittel CE, Smith WW, DeFranco DB, Ross CA (2006) Depletion of CBP is directly linked with cellular toxicity caused by mutant huntingtin. Neurobiol Dis 23:543-551.

Khoshnan A, Ko J, Watkin EE, Paige LA, Reinhart PH, Patterson PH (2004) Activation of the $\mathrm{I} \kappa \mathrm{B}$ kinase complex and nuclear factor- $\kappa \mathrm{B}$ contributes to mutant huntingtin neurotoxicity. J Neurosci 24:7999-8008.

Kim YJ, Yi Y, Sapp E, Wang Y, Cuiffo B, Kegel KB, Qin ZH, Aronin N, DiFiglia M (2001) Caspase 3- cleaved N-terminal fragments of wild-type and mutant huntingtin are present in normal and Huntington's disease brains, associate with membranes, and undergo calpain-dependent proteolysis. Proc Natl Acad Sci U S A 98:12784-12789.

Langbehn DR, Brinkman RR, Falush D, Paulsen JS, Hayden MR (2004) A new model for prediction of the age of onset and penetrance for Huntington's disease based on CAG length. Clin Genet 65:267-277.

Levkau B, Scatena M, Giachelli CM, Ross R, Raines EW (1999) Apoptosis overrides survival signals through a caspase-mediated dominant-negative NF-kappa B loop. Nat Cell Biol 1:227-233.

Li L, Murphy TH, Hayden MR, Raymond LA (2004) Enhanced striatal NR2B-containing $N$-methyl-D-aspartate receptor-mediated synaptic currents in a mouse model of Huntington disease. J Neurophysiol 92:2738-2746.

Liang ZQ, Wang XX, Wang Y, Chuang DM, DiFiglia M, Chase TN, Qin ZH (2005) Susceptibility of striatal neurons to excitotoxic injury correlates with basal levels of Bcl-2 and the induction of P53 and c-Myc immunoreactivity. Neurobiol Dis 20:562-573.

Liu X, Kim CN, Pohl J, Wang X (1996) Purification and characterization of an interleukin-1ß-converting enzyme family protease that activates cysteine protease P32 (CPP32). J Biol Chem 271:13371-13376.

MacLachlan TK, El-Deiry WS (2002) Apoptotic threshold is lowered by p53 transactivation of caspase-6. Proc Natl Acad Sci U S A 99:9492-9497.

Mangiarini L, Sathasivam K, Seller M, Cozens B, Harper A, Hetherington C, Lawton M, Trottier Y, Lehrach H, Davies SW, Bates GP (1996) Exon 1 of the HD gene with an expanded CAG repeat is sufficient to cause a progressive neurological phenotype in transgenic mice. Cell 87:493-506.

Mazars A, Fernandez-Vidal A, Mondesert O, Lorenzo C, Prévost G, Ducommun 
B, Payrastre B, Racaud-Sultan C, Manenti S (2009) A caspase-dependent cleavage of $\mathrm{CDC} 25 \mathrm{~A}$ generates an active fragment activating cyclindependent kinase 2 during apoptosis. Cell Death Differ 16:208-218.

Milnerwood AJ, Gladding CM, Pouladi MA, Kaufman AM, Hines RM, Boyd JD, Ko RW, Vasuta OC, Graham RK, Hayden MR, Murphy TH, Raymond LA (2010) Early increase in extrasynaptic NMDA receptor signaling and expression contributes to phenotype onset in Huntington's disease mice. Neuron 65:178-190.

Morrison RS, Wenzel HJ, Kinoshita Y, Robbins CA, Donehower LA, Schwartzkroin PA (1996) Loss of the p53 tumor suppressor gene protects neurons from kainate-induced cell death. J Neurosci 16:1337-1345.

Morrison RS, Kinoshita Y, Johnson MD, Guo W, Garden GA (2003) p53dependent cell death signaling in neurons. Neurochem Res 28:15-27.

Nikolaev A, McLaughlin T, O’Leary DD, Tessier-Lavigne M (2009) APP binds DR6 to trigger axon pruning and neuron death via distinct caspases. Nature 457:981-989.

Okamoto S, Pouladi MA, Talantova M, Yao D, Xia P, Ehrnhoefer DE, Zaidi R, Clemente A, Kaul M, Graham RK, Zhang D, Vincent Chen HS, Tong G, Hayden MR, Lipton SA (2009) Balance between synaptic versus extrasynaptic NMDA receptor activity influences inclusions and neurotoxicity of mutant huntingtin. Nat Med 15:1407-1413.

Pompl PN, Yemul S, Xiang Z, Ho L, Haroutunian V, Purohit D, Mohs R, Pasinetti GM (2003) Caspase gene expression in the brain as a function of the clinical progression of Alzheimer disease. Arch Neurol 60:369-376.

Pouladi MA, Graham RK, Karasinska JM, Xie Y, Santos RD, Petersén A, Hayden MR (2009) Prevention of depressive behaviour in the YAC128 mouse model of Huntington disease by mutation at residue 586 of huntingtin. Brain 132:919-932.

Qin ZH, Chen RW, Wang Y, Nakai M, Chuang DM, Chase TN (1999) Nuclear factor $\kappa \mathrm{B}$ nuclear translocation upregulates c-Myc and p53 expression during NMDA receptor-mediated apoptosis in rat striatum. J Neurosci 19:4023-4033.

Ratovitski T, Nakamura M, D’Ambola J, Chighladze E, Liang Y, Wang W, Graham R, Hayden MR, Borchelt DR, Hirschhorn RR, Ross CA (2007) $\mathrm{N}$-terminal proteolysis of full-length mutant huntingtin in an inducible PC12 cell model of Huntington's disease. Cell Cycle 6:2970-2981.

Rouaux C, Loeffler JP, Boutillier AL (2004) Targeting CREB-binding protein (CBP) loss of function as a therapeutic strategy in neurological disorders. Biochem Pharmacol 68:1157-1164.

Saganich MJ, Schroeder BE, Galvan V, Bredesen DE, Koo EH, Heinemann SF (2006) Deficits in synaptic transmission and learning in amyloid precursor protein (APP) transgenic mice require C-terminal cleavage of APP. J Neurosci 26:13428-13436.

Seong IS, Ivanova E, Lee JM, Choo YS, Fossale E, Anderson M, Gusella JF, Laramie JM, Myers RH, Lesort M, MacDonald ME (2005) HD CAG repeat implicates a dominant property of huntingtin in mitochondrial energy metabolism. Hum Mol Genet 14:2871-2880.

Slow EJ, van Raamsdonk J, Rogers D, Coleman SH, Graham RK, Deng Y, Oh R, Bissada N, Hossain SM, Yang YZ, Li XJ, Simpson EM, Gutekunst CA, Leavitt BR, Hayden MR (2003) Selective striatal neuronal loss in a YAC128 mouse model of Huntington disease. Hum Mol Genet 12: 1555-1567.

Slow EJ, Graham RK, Osmand AP, Devon RS, Lu G, Deng Y, Pearson J, Vaid K, Bissada N, Wetzel R, Leavitt BR, Hayden MR (2005) Absence of behavioral abnormalities and neurodegeneration in vivo despite widespread neuronal huntingtin inclusions. Proc Natl Acad Sci U S A 102: 11402-11407.

Stadelmann C, Deckwerth TL, Srinivasan A, Bancher C, Brück W, Jellinger K, Lassmann H (1999) Activation of caspase- 3 in single neurons and autophagic granules of granulovacuolar degeneration in Alzheimer's disease. Evidence for apoptotic cell death. Am J Pathol 155:1459-1466.

Steffan JS, Kazantsev A, Spasic-Boskovic O, Greenwald M, Zhu YZ, Gohler H, Wanker EE, Bates GP, Housman DE, Thompson LM (2000) The Huntington's disease protein interacts with p53 and CREB-binding protein and represses transcription. Proc Natl Acad Sci U S A 97:6763-6768.
Taylor-Robinson SD, Weeks RA, Bryant DJ, Sargentoni J, Marcus CD, Harding AE, Brooks DJ (1996) Proton magnetic resonance spectroscopy in Huntington's disease: evidence in favour of the glutamate excitotoxic theory. Mov Disord 11:167-173.

Tesco G, Koh YH, Kang EL, Cameron AN, Das S, Sena-Esteves M, Hiltunen M, Yang SH, Zhong Z, Shen Y, Simpkins JW, Tanzi RE (2007) Depletion of GGA3 stabilizes BACE and enhances beta-secretase activity. Neuron 54:721-737.

Thornberry NA, Rano TA, Peterson EP, Rasper DM, Timkey T, Garcia-Calvo M, Houtzager VM, Nordstrom PA, Roy S, Vaillancourt JP, Chapman KT, Nicholson DW (1997) A combinatorial approach defines specificities of members of the caspase family and granzyme B. Functional relationships established for key mediators of apoptosis. J Biol Chem 272:17907-17911.

Thornberry NA, Chapman KT, Nicholson DW (2000) Determination of caspase specificities using a peptide combinatorial library. Methods Enzymol 322:100-110.

Van Raamsdonk JM, Murphy Z, Slow EJ, Leavitt BR, Hayden MR (2005) Selective degeneration and nuclear localization of mutant Huntingtin in the YAC128 mouse model of Huntington disease. Hum Mol Genet 14:3823-3835.

Vonsattel JP, Myers RH, Stevens TJ, Ferrante RJ, Bird ED, Richardson EP Jr (1985) Neuropathological classification of Huntington's disease. J Neuropathol Exp Neurol 44:559-577.

Warby SC, Doty CN, Graham RK, Carroll JB, Yang YZ, Singaraja RR, Overall CM, Hayden MR (2008) Activated caspase-6 and caspase-6-cleaved fragments of huntingtin specifically colocalize in the nucleus. Hum Mol Genet 17:2390-2404.

Wellington CL, Singaraja R, Ellerby L, Savill J, Roy S, Leavitt B, Cattaneo E, Hackam A, Sharp A, Thornberry N, Nicholson DW, Bredesen DE, Hayden MR (2000) Inhibiting caspase cleavage of huntingtin reduces toxicity and aggregate formation in neuronal and nonneuronal cells. J Biol Chem 275:19831-19838.

Wellington CL, Ellerby LM, Gutekunst CA, Rogers D, Warby S, Graham RK, Loubser O, van Raamsdonk J, Singaraja R, Yang YZ, Gafni J, Bredesen D, Hersch SM, Leavitt BR, Roy S, Nicholson DW, Hayden MR (2002) Caspase cleavage of mutant huntingtin precedes neurodegeneration in Huntington's disease. J Neurosci 22:7862-7872.

Xanthoudakis S, Roy S, Rasper D, Hennessey T, Aubin Y, Cassady R, Tawa P, Ruel R, Rosen A, Nicholson DW (1999) Hsp60 accelerates the maturation of pro-caspase- 3 by upstream activator proteases during apoptosis. EMBO J 18:2049-2056.

Xiang H, Kinoshita Y, Knudson CM, Korsmeyer SJ, Schwartzkroin PA, Morrison RS (1998) Bax involvement in p53-mediated neuronal cell death. J Neurosci 18:1363-1373.

Yu ZX, Li SH, Evans J, Pillarisetti A, Li H, Li XJ (2003) Mutant huntingtin causes context-dependent neurodegeneration in mice with Huntington's disease. J Neurosci 23:2193-2202.

Zeron MM, Hansson O, Chen N, Wellington CL, Leavitt BR, Brundin P, Hayden MR, Raymond LA (2002) Increased sensitivity to $N$-methyl-Daspartate receptor-mediated excitotoxicity in a mouse model of Huntington's disease. Neuron 33:849-860.

Zeron MM, Fernandes HB, Krebs C, Shehadeh J, Wellington CL, Leavitt BR, Baimbridge KG, Hayden MR, Raymond LA (2004) Potentiation of NMDA receptor-mediated excitotoxicity linked with intrinsic apoptotic pathway in YAC transgenic mouse model of Huntington's disease. Mol Cell Neurosci 25:469-479.

Zhang J, Gorostiza OF, Tang H, Bredesen DE, Galvan V (2010) Reversal of learning deficits in hAPP transgenic mice carrying a mutation at Asp664: a role for early experience. Behav Brain Res 206:202-207.

Zhang WH, Wang X, Narayanan M, Zhang Y, Huo C, Reed JC, Friedlander RM (2003) Fundamental role of the Rip2/caspase-1 pathway in hypoxia and ischemia-induced neuronal cell death. Proc Natl Acad Sci U S A 100: 16012-16017. 